rest is sufficient. In vaginal surgery the position is less satisfactory, and I must admit having had two deaths from embolism-one in a patient with a stiff leg, and the other in a patient over 80 . With the usual lithotomy supports, pressure on the calves is unavoidable, and they should be modified so that the legs can swing inside them.-I am, etc.,

Chichester, Sussex

BRYAN WILLIAMS

\section{Uneasy Relations}

SIR,-I read with interest the contribution of Dr. A. Paton (6 March, p. 554). His observations on the responsibilities to each other of consultants of differing disciplines are wise and deserve to be widely read. However, I cannot let pass his strictures on members of my own specialty-anaesthesia. "Notorious expanders of empire" we may be labelled, but expansion has occurred to fill a therapeutic vacuum, and not as a result of clashes with medical and surgical colleagues. Our involvement in intensive care units is in part due to their evolution from respiratory units and postoperative wards, but also because members of other specialties have been reluctant, in many hospitals, to accept the increased workload which can seldom be confined to office hours.

Anaesthetic out-patient clinics are another thing. But here again we have a contribution to make, and we are able to relieve some of the acute pressure on surgical outpatient clinics. In my own clinic I see upwards of 500 patients each year. Therapeutic procedures are confined to treatment of simple iron deficiency anaemia, reduction of obesity, referral for dental treatment, physiotherapy for chronic chest disease, and simple psychological support. We are also a second line of defence in that we offer the patient a further chance to ask questions. Many do not ask the questions they wish at the surgical consultation because of shortage of time, fear, or inability to think of them at short notice. In the outpatient clinic the observant and tactful anaesthetist can do much to smooth the preparation of the patient for surgery.

As anaesthetists, I believe that our main duty is to provide safe and competent clinical care for patients undergoing surgical operations. In this the technical side of anaesthesia is of paramount importance. But we must not neglect areas of legitimate interest outside the operating theatre which make us the modern anaesthetist today.-I am, etc., Southend General Hospital,
Southend on Sea, Essex

R. S. AtKINSON

\section{A Pyschiatrist in Space?}

SIR,-Your leading article (30 January, p. 245) raises some vital issues regarding the place of psychiatry in society and the function and potential of psychotherapy.

You ask "what is so special about psychotherapy from a doctor"? In my view the special quality emerges when psychotherapy is of a supportive nature, depending upon the patient's belief in the omnipotence of the doctor-to use Balint's phrase, his "apostolic function". This is a positive transference technique which parallels a child's total belief and trust in his parents. It is easy to understand under these circumstances the value of being a doctor, and how this quality lends itself to a "special relationship". With analytically-orientated psychotherapy, the aim is not to support a dependent relationship but to examine it openly. It is necessary to interpret the dependency and allow ambivalent feelings to be expressed; in other words, the negative transference must be dealt with. Under these circumstances, the "special" quality of psychotherapy from a doctor is of less importance. What is more relevant is the training and experience of the psychotherapist, be he a doctor or from a different discipline.

Last summer you published a leading article entitled "Who Should Do Psychotherapy?" (13 June, p. 617). The main choice appeared to be between the appointment of 480 more psychiatrists (Wing's estimate) and opening the field of psychotherapy to nonmedical disciplines. I think the problem is reflected in your present leader when you state that "the voice of mission control" was psychotherapy itself. I would agree completely with this view; in which case the contribution of psychotherapy would be to help mission control in coping with the conflicts that arise in relationship to astronauts in space. Obviously, the psychiatrist could take over the problem and try to deal with it himself, but this would imply the inability of mission control to cope with the variou stresses. To my mind, the situation is very similar to that of a hospital trying to function as a therapeutic community. I have no doubt that the main function of a psychotherapist in a hospital setting is to offer himself to staff of all disciplines, to help them with the stresses and conflicts that arise in the course of everyday work. The psychotherapist's skill should be used to impart to others the better understanding of psycho-dynamic principles and understanding of the complex relationships that occur.

You ask "Can psychiatrists by the nature of their training and experiences ever be of help under such circumstances?" I believe that the answer is "yes" and would focus on the value of group psychotherapeutic techniques. People working with groups have invariably to face stress and tension resulting from inter-personal relationships. It is really of little importance what the specific nature of the conflict is, and the emphasis should be upon the dynamics of the relationships surrounding the conflict. In terms of space flight, it would seem that the astronauts depend upon the skill and experience of mission control, rather in the same way that a patient will become dependent upon a doctor working with a positive transference technique. On the other hand, you state that "astronauts are essentially self-selecting individuals ... . whose ability to complete the training programme excludes the possibility that they may not be able to cope under pressure." Surely this is an area of conflict in which it would be reasonable to explore the problem in depth. Perhaps this is where psychiatrists trained in group dynamics would be of potential assistance?

To return once more to the hospital setting and the whole question of who should do psychotherapy, I am convinced that the immediate task should be that of helping people of all disciplines to improve their skills. At Halliwick Hospital, for example there are some twelve outpatient psychotherapy groups in existence of which half are being run by non-medical staff-that is, nurses, psychiatric social workers, and occupational therapists. All staff meet with one of the consultant psychotherapists once a week to discuss their work. We consider it essential that this work continue and grow and I can see no alternative at this time to the problem of the psychotherapeutic needs of the country as a whole. I am convinced that we have to get away from the "special" quality of psychotherapy from a doctor, and turn to non-medical staff whose potential in this field is unlimited. The focus should be the improvement of training facilities in psychotherapeutic techniques for all staff, rather than to collude in the belief of the omnipotence and omniscience of "the doctor".-I am, etc.,

LIONEL KREEGER

Halliwick Hospital

London N.11

Accident and Emergency Services

SIR,-In recent letters on the problems of staffing accident and emergency departments it has been stated that the appointment of "one consultant surgeon will not solve the problem of providing a doctor on duty in the department" (16 January, p. 177), and that "Those who advocate a full-time consultant working in the accident and emergency department still fail to realize that the majority of patients attend outside the 9-5 day of the consultant" (27 February, p. 506)

Of the first 10,000 new patients to attend the accident and emergency department of the Leeds General Infirmary this year, 5,036 attended during my working hours. During this period (1 January to 27 February) there were 5,277 return visits, of which 4,829 were made during my working hours.

If these figures are representative they show that half the new patients and $90 \%$ of the return visit patients attend an accident and emergency department while the full-time surgeon-in-charge is available for consultation. Listed among the "return visits" are a number of patients who originally attended during the previous evening or night and who, after their initial treatment, had been asked to return the following morning for me to see them. I was thus able to examine them and review their treatment within a few hours of their first visit.

However, there still remains the problem of patients who arrive outside "working hours" and who require immediate treatment. The consultant's contribution to the care of these patients is made through the training of his junior staff, by making sure that essential equipment is available, and by establishing lines of communication so that expert help can be called for when necessary.-I am, etc.

David H. WILsoN

Accident and Emergency Department,
General Infirmary, Leeds

\section{Treating the Mentally Subnormal}

SIR,-The concept behind the Mental Health Act 1959, was to place psychiatric patients on the same basis, as far as possible, as 